MUSICA THEORICA 201808

SCIENTIFIC ARTICLE

Data do recebimento: $10 / 08 / 2018$

Data da aprovação final: 07/09/2018

\title{
O Compositor e a Teoria
}

\section{The Composer and the Theory}

\author{
Achille Picchi \\ UNESP - Universidade Estadual Paulista \\ achillepicchi@gmail.com
}

Resumo: Trata-se de refletir sobre a posição da teoria na composição musical e na vida composicional do compositor. Coloca-se a técnica a partir do insight e da ideia; depois trata-se da expertise como vivência da técnica composicional onde se encaixam a técnica pessoal como artesanato e aplicação criativa na resolução de problemas autoimpostos. Por fim é feito um paralelo com o ensaio A Filosofia da Composição, de Edgar Allan Poe para reconhecer e ilustrar o anteriormente refletido.

Palavras-chave: teoria musical; composição musical; insight; expertise; resolução de problemas.

\begin{abstract}
This article reflects on the role of theory in the musical composition process and also in the creative life of the composer. We start with the concepts of insight and idea, to reach the concept of expertise as the compositional technique of a personal style, where fit artisanat and creative application as the resolution of self imposed problems. Finally, a comparison is made with the essay The Philosophy of Composition by Edgar Allan Poe to illustrate the previous reflections.
\end{abstract}

Keywords: musical theory; musical composition; insight; expertise; problem resolution. 


\section{1 - Introdução}

Avant donc que d'écrire apprenez à penser.

Selon que notre idée est plus ou moins obscure La expression. La suit, ou moins nette, ou plus purê;

Ce que l'on conçoit bien, s'enonce clairement. Boileau "L'Art Poétique"

Onde se poderia colocar a teoria relativamente ao compositor? Numa visada ampla e geral, certamente colocaríamos antes da composição. Talvez mesmo antes do compositor como criador completo. O que quer dizer na formação, ou seja, na aquisição de cultura musical, bagagem, repertório, conhecimento de outras obras - e, daí conhecimento analítico -, habilidades específicas como, por exemplo, entre outras, dominar um instrumento musical.

De fato, o compositor Camargo Guarnieri costumava dizer a seus discípulos e alunos que o compositor é aquele que estuda todas as técnicas, conhece todas as obras mais importantes dos mais importantes compositores, estuda e domina toda a teoria da música para que, quando sentar para compor, esqueça tudo. E componha! ${ }^{1}$

Assim pensando e sob esse aspecto, o domínio, digamos, da ciência composicional se aprende. E para tanto teremos de ir às suas bases, seus fundamentos. Refere a isso Luciano Berio (Berio, s.d., p. 63) ao dizer que "adquiridas determinadas bases, um jovem deve continuar sozinho e ir à procura de tudo aquilo que lhe convém". E que, para ele, "as bases são, em primeiro lugar o contraponto e, em segundo, a análise".

Então de alguma forma está posto que a composição musical se assenta em bases técnicas. A técnica composicional, dessa forma, pertenceria ao métier ${ }^{2}$ do compositor, como elemento formador assim como desenvolvedor, como uma ferramenta de aperfeiçoamento.

E a técnica composicional, adquirida e vivenciada ao longo do trabalho criativo, estará sedimentada na teoria, isto é, nos processos formativos mencionados antes, ancorados, agora, no conhecimento e uso, bem como nas visões relativas à composição que se vão ao longo do tempo instalando, moldando o chamado estilo composicional e formando a individualidade de cada compositor.

\footnotetext{
${ }^{1}$ Dito diversas vezes a mim, enquanto aluno e que aqui reproduzo por entender como um preceito daquele grande mestre.

2 Usa-se aqui métier no seu sentido técnico de alguém que domina o ofício, o que parece mais próximo ao original latino mester.
} 


\section{2 - A Composição: Processos}

Parece indubitável que a criação, seja de que natureza for ou qual meio use para se materializar, começa na mente.

Tempos houve em que era assumida a ideia de que somente pessoas com 'condições mentais especiais' tinham prerrogativas composicionais. As ligações com habilidades, muitas vezes excepcionais, observadas nessas pessoas levavam a crer no fato que, por alguma complexidade natural e inclinação, elas eram mais capazes (dotadas, se dizia, então) que outras de empreender o caminho criativo efetivo. E, por efetivo, aqui se quer dizer do que é levado a efeito de fato, isto é, para contextos determinados, satisfatoriamente, e, por vezes, excedendo esse satisfatório.

Associado a isso, esteve sempre o conceito de gênio o qual, partindo do estatuído por Aristóteles como o estro humano, no sentido da capacidade e percorrendo a história ocidental de maneira horizontal, chegou a essa teleologia da capacidade do homem, ou seja, o excepcional, o não conseguível por todos, enfim, o talento inato e inegável, que justificava a obra e sua consecução.

A psicologia cognitiva, há já algum tempo, estuda os processos criativos em geral - e musicais, como a composição, em particular. E, de certa forma minimizou, ou talvez adequou, a condição de gênio à pesquisa da expertise no processo criativo.

Através de um grande número de relatos de compositores, do passado e da atualidade, pode-se perceber que há uma certa unanimidade acerca do processo composicional: primeiro a inspiração (e o insight), depois a realização (e a elaboração). Desses dois, digamos, estágios, parece que há menos dificuldade em se relatar o segundo, ou o como, relativamente ao primeiro, ou a ideia.

No entanto, segundo pesquisas, também hoje se percebe que há, quase sempre, um quadro geral formado na cabeça do compositor antes de começar a realização. Isto é o que talvez quisesse ter dito, de modo sintético, Leonardo da Vinci quando enunciou l'arte è una cosa mentale.

O próprio Berio, já referido (Berio, s.d., p. 75), noutra entrevista, dizia que para ele "a primeira ideia de um trabalho é sempre global e, aos poucos, enquanto o trabalho avança, vou definindo os detalhes. Não poderia ser mais simples do que isso".

Quase a demonstrar a interpenetração, ainda que randômica, do insight e de sua continuação como obra na mente. Mas, para tanto, "enquanto o trabalho avança", as ferramentas do conhecimento deverão já intrinsicamente estar introjetadas, especialmente para a pesquisa que o compositor certamente irá empreender. Pesquisa essa que, aqui, supõe escolhas, mais que certamente. Como diz Mariza Rezende (Ferraz 2007, p. 77), “compor significa entre outras 
coisas fazer escolhas. Compor significa muitas coisas, entre elas poder fazer escolhas".

Esse "poder fazer escolhas", eivado de liberdade como parece estar, no entanto não exime o fato de que o poder para fazer as escolhas reside no conhecimento (trazido da bagagem, do repertório, do estudo, etc., como já mencionado) transformado em métier, ofício, pela continuidade do fazer musical com consciência.

De fato, “a pesquisa sobre os processos criativos [...] tem voltado sua atenção para a influência que fatores sociais, culturais e históricos têm no desenvolvimento da criatividade [...] Dessa forma há interesse crescente [...] em investigar a influência que processos comuns de pensamento e a experiência específica em um domínio, a expertise, exercem no processo e na produção criativa" (Nogueira 2010, p. 64-65).

Inegavelmente um criador é um transformador. É aquele que, num domínio de interesse, transforma tudo à sua volta no seu ponto de vista artístico - nesse caso, em música. E, como indivíduo, reflete condições de seu meio circunstante, gostos, críticas, vivências, etc.: "a arte é, essencialmente, uma expressão individual" (Chavez 1986, p. 17).

Silvio Ferraz (2005, p. 96) chama a atenção para a materialidade da composição como um campo de forças: "quando o compositor escreve sua música ele se vale de coisas, se vale de formas musicais, se vale de blocos sonoros, de acordes, até mesmo de alguns acordes cheios de nomes ou de melodias cheias de história [...] este é o material". O material está ali à disposição do compositor. Dizendo com Heidegger, há materialidade na arte (Heidegger 1999, p. 13): "há pedra no monumento. Há madeira na escultura talhada. Há cor no quadro. Há som na obra falada. Há sonoridade na obra musical". É o que Heidegger chamaria de "caráter coisal" da obra musical: "a obra de arte também é uma coisa, na medida em que é em geral algo que é" (idem, p. 14), coisa por sua existência, materialidade, pelas propriedades que reúne em si. "As coisas são o suporte de suas características" (Castello Branco 2012, p. 75) e assim mostram as duas facetas indistintas de intenção de ser e a intencionalidade de existir, como por exemplo no caso da música, numa partitura.

Quando a ideia aparece - e segundo o impulso criativo, inclusive já constatado pela psicologia cognitiva, ela sempre aparece -, as adaptações e transformações precisam começar a ser feitas "para pôr ordem no caos", como dizia Stravinsky (1996), para que a obra apareça. Sloboda também registra, através de relatos de compositores, a existência de dois momentos gerais e abrangentes na composição e diz que o compositor "não é tão consciente de suas ideias quanto é possuído por elas" (Sloboda 2008, p. 151). O momento da chamada "execução", quando então o compositor se valeria dos processos conscientes e intencionais de desdobramento e construção da obra através de seu 
conhecimento, habilidade, técnica “implica a existência de um repertório [...] de maneiras de estender e construir a partir de materiais dados, descobrindo e usando as propriedades que são inerentes a eles, segundo princípios" (Sloboda 2008, p. 152, negrito meu). Note-se, aqui, a palavra princípios que, naturalmente, está empregada para significar normas, conjunto de normas, padrões, etc., o que nos remete a conceituações teóricas de fundamento, já que princípios também alude à origem do conhecimento como base. É claro que os princípios, colocados aqui por Sloboda, podem ser os conhecidos ou os novos, forjados dentro de novos horizontes técnicos. Isto nos remete ao fato de que é tão criativo usar como inventar soluções construtivas para a consecução da obra. Assim, é preciso aqui ressaltar, com o autor, a consciência e a intenção do compositor quando de seu uso a partir do insight para o desenvolvimento da composição.

Este é problema antigo, o embate da ideia, do insight, e o desenvolvimento do que será a obra, o processo construtivo, de realização integral.

Certa feita Claudio Monteverdi expressou, em 1638, no prefácio ao oitavo livro de madrigais, o seguinte julgamento: "considero como sendo três as paixões ou emoções da alma: raiva, serenidade e humildade. Os melhores filósofos o afirmaram [...] e a arte da música as manifesta nesses três termos: agitado, suave e moderado". Entretanto, segundo o compositor, o stile concitato, sendo tão necessário à expressão musical, não havia ainda sido explorado adequadamente - ou mesmo originalmente. Por isso, após a primeira apresentação de obras que realizavam esse modus musicantem, diz ele (Morgenstern 1956, p. 22-23, negritos do autor):

Tendo tido sucesso no meu método de representar a raiva, continuei, com grande zelo, minhas investigações e escrevi diversas composições, tanto eclesiásticas quanto de câmera. Elas encontraram tanto eco nos compositores que eles não só falaram em favor delas, mas, para minha grande alegria e honra, escreveram obras imitando-as.

Interessante notar que nas observações do grande italiano comparecem as palavras investigação e método, pois a composição musical procede sempre por posicionamento dos resultados de uma investigação e por sedimentação através de um método, seja existente, seja novo - ou como se poderia chamar mais recentemente, técnica composicional.

Podemos assim situar muito bem Monteverdi como um exemplo de escola, na máxima de Stravinsky: “temos um dever perante a música que é inventá-la" (Stravinsky 1996, p. 55). 


\section{3 - Insight: Dialética Composicional}

No princípio é a ideia. Como diz Copland (2013, p. 31), “um dos mistérios da composição é o problema da inspiração", de onde partem as obras; ou seja, como tudo começa.

Tudo começa com a ideia musical. Entretanto é preciso que se diga que isso não representa problema ou sequer mistério para o compositor, como talvez representasse para o não músico. Envolvido como está sempre com a intenção de compor, para ele o aparecimento de ideias é fluxo contínuo. Ele as coleciona - ou as descarta, conforme o caso. A ideia é só o êmulo da produção musical, da realização da obra que é a composição. Para o compositor o que interessa é a disposição em compor e deixar registrada a intencionalidade, o texto musical, fim último de suas escolhas e primeiro roteiro da obra para sua mediação quando de sua execução. ${ }^{3}$

Nesse momento seria talvez útil distinguir - ou separar - ideia de insight, ${ }^{4}$ porque o compositor, sempre aberto e disponível às ideias em fluência em sua mente, examina-as e, por vezes, surge mentalmente um plano geral da obra. Mesmo um do processo composicional e, até, do objetivo final.

Dizia o compositor Telemann, quem sabe com a ingenuidade dos experts: "se não houver nada de novo a ser encontrado na melodia, então devemos buscar na harmonia" 5 (Morgenstern 1956, p. 41).

Copland (2010, p.32) menciona que o compositor profissional "pode sentar-se diariamente à sua mesa e produzir algum tipo de música. Haverá dias em que ele se sentirá melhor do que em outros; mas o fato básico é a sua capacidade de compor. A inspiração, às vezes, não passa de um subproduto".

Analisando mais de perto a afirmação de Copland, vemos duas coisas importantes: a disposição composição versus capacidade de compor; e a não dependência necessária de uma inspiração. Isto talvez nos mostre a indivisibilidade que tentávamos relacionar ao separar ideia/inspiração de insight,

\footnotetext{
${ }^{3}$ Sobre a intenção e a intencionalidade na música, redigi um texto que está presentemente no prelo e que versa fundamentalmente sobre três aspectos fundamentais da composição: a intenção do compositor em realizar a obra, sempre musicalmente, a qual é inexpugnável, mas traçável através do guia, que se pode designar por partitura, onde registra sua intencionalidade através de escolhas que chamei akrásicas; e, por fim, a abertura que esta última favorece ao intérprete através da análise para retraçar a intencionalidade do compositor apondo suas intenções que, quando bem fundamentadas em ferramental analítico e posicionamento pessoal claro, poderão ser de multifária natureza e ideário vário, fazendo assim de cada performance uma intencionalidade.

${ }^{4}$ Numa tradução livre poderíamos dizer "visão interior" ou quiçá vinda do interior para classificar insight.

${ }^{5}$ Numa carta ao compositor C. H. Graun, de 1751-52. Faz lembrar a afirmação de Berio: "nada mais simples que isso"...
} 
já que, como dizia Honnegger6 (Morgenstern 1956, p.467), “um compositor digno desse nome deve prever tudo". E isso, naturalmente, envolve o sentimento de uma totalidade e, ao mesmo tempo, é provável, procedimentos através dos quais consegui-la.

O mesmo Honnegger (idem, ibidem) diz que aquele compositor que tem esse controle e essa consciência, precisará "somente verificar com seus ouvidos o que seu cérebro concebeu".

Chegamos, enfim, ao fato de que a teoria exerce sobre o compositor, consciente e inconscientemente, uma submissão àquele conhecimento, por várias formas apreendido e tornado verdade para o criador ao longo de um caminho provedor do desenvolvimento e aperfeiçoamento de seu métier, seu ofício.

Advindo da ideia de 'caos' stravinskyana, a famosa asserção de Schoenberg (1996, p. 27) mostra a técnica composicional definitivamente assentada no ofício que o compositor busca na maestria de seu domínio: "sem organização, a música seria uma massa amorfa, tão ininteligível quanto um ensaio sem pontuação, ou tão desconexa quanto um diálogo que saltasse despropositadamente de um argumento a outro".

\section{4 - Expertise e Técnica}

\section{1 - Técnica pessoal}

Logo, definitivamente composição musical é trabalho. Mais que inspiração, boas ou mesmo geniais ideias, o insight leva ao trabalho.

Constata Etienne Souriau (1973, p. 99): “Que a arte possui todos os caracteres visíveis do trabalho, não resta dúvida [...] para se formar um músico, executante ou compositor, é preciso longo esforço, iniciado precocemente". E acaba por tratar como preconceito os que contestam a ideia de que tem de haver uma formação técnica, como ele diz, "precoce e dura". E lança um repto aos que pensam - e valorizam - o autodidatismo e a espontaneidade, assim chamados, referindo-se aos "artistas verdadeiramente grandes", onde verifica que "todos foram grandes laboriosos" (Idem, ibidem) 7 . Percebe-se que o esteta francês está, com esta afirmação decidida, interpenetrando fronteiras, ou seja, desde a formação até a vida expressiva do artista há a técnica a considerar como constante e integrante e, ao que parece para ele, indivisível.

\footnotetext{
${ }^{6}$ Em seu livro sobre composição e sobre ele mesmo como compositor, Je suis compositeur.

7 Parece-nos que Souriau está colocando aqui, sutilmente, um juízo de valor da obra que tenha labor técnico considerado e outra que não, quando diz "didatismo" e "espontaneidade", não invalidando o posicionamento do trabalho na obra de arte; entretanto, esta discussão é grande demais e fora do escopo das ideias aqui apresentadas.
} 
Ao termo que se chega, então, é que a técnica composicional, formada a partir do conhecimento e convivência com a teoria, e maturada através da vivência destes com o precípuo e fundamental objetivo de validar e suportar a verdade expressiva da criação pretendida pelo compositor, é amálgama completo e visceral na obra deste.

Entretanto Stravinsky afirma peremptoriamente que a técnica "não é uma ciência que se possa ensinar nem é aprendizagem, nem erudição, nem sequer conhecimento de como fazer alguma coisa. É criação e, como tal, constantemente nova" (Stravinsky e Craft 2010, p. 19). O que claramente não nega o posicionamento de Souriau, anterior, quanto ao fato da obra ser fruto de trabalho. Porém, ela se mostra através do resultado do trabalho, ou seja, da técnica que a realizou, assim confirmando, voltando a Heidegger (2004, p.19), que o que dá "consistência e sua nuclearidade e que origina simultaneamente o tipo do seu afluxo sensível, o colorido, o sonoro, a dureza, o maciço é a materialidade". O "caráter coisal", já apontado antes, da composição musical, resultante é, "manifestamente a matéria de que consta" (Heidegger 2004, p. 19). Isto, portanto, nos leva do que está expresso, a escrita, a partitura, o código a ser decifrado, para a escritura, ou o que não está expresso pela escrita, o que jaz por detrás da escrita, para além do código: a música.

A ideia da técnica composicional, como a habilidade de reunir insight, estruturação organizacional, sentido e realização final comtempla a ontologia musical e, nela, se faz passado e presente, tradição e ruptura, conservadorismo e vanguarda. Ou, como diria Adorno, na composição só conta o realizado (Picchi 2015, p. 487).

Dessa forma, a técnica composicional, seja entronizada através da experiência e/ou tradição, seja realizada por meio de inovação individuada, envolve a necessária e inescapável manipulação da teoria sob o âmbito da vivência, tornando-se, assim, para o compositor, uma expertise própria; e talvez, se assim for o caso, fundamentando um estilo. É possível que, visto desta maneira, justifique-se a visão stravinskyana de "não-ciência, não-aprendizado, não-erudição", etc., para a técnica, pois é própria do criador e, quase sempre, para cada obra. O próprio Stravinsky mencionava que quando ouvia falar que tal compositor tinha uma técnica particular, queria sempre conhecer o compositor e não sua técnica (Stravinsky 1996).

Contudo, pode-se dividir esta expertise em duas regiões, no sentido do entendimento, como sendo uma o artesanato, então sujeito ao aprendizado e outra a aplicação criativa.

Diz Mário de Andrade, em O Artista e o Artesão (1938, p. 11), "se perscrutarmos a existência de qualquer grande pintor, escultor, desenhista ou músico, encontramos, sempre, por detrás do artista o artesão". E, por artesão, 
obviamente o intelectual paulista está situando o manipulador do material que, com sua possibilidade 'instrumental' (no sentido da techné grega), realiza e mesmo prevê o caminho que a obra vai tomando. Assim, completa que "nos processos de movimentar o material, a arte se confunde quase inteiramente com o artesanato" e "todo artista tem de ser ao mesmo tempo artesão" (Andrade 1938, p. 11). Mas afirma que é preciso distinguir técnica (que ele traduz por treino, prática) de conhecimento técnico, que, segundo ele, seria a vida intelectual da técnica (idem, p. 24). E é interessante notar, neste ponto, como a ideia de indivisibilidade da manipulação técnica do material com objetivo de construir a obra, tem a ver com a expressividade pessoal. Essa complementaridade técnica/expressão seria a verdade expressiva da criação pretendida, como mais atrás se colocou.

A técnica é, afinal, uma condição pessoal de uso do compositor e desenvolve-se junto com o procedimento composicional deste - e de obra para obra, o que significa através de práxis individuais. A teoria não se limita a fundamentar e aparelhar as escolhas e caminhos composicionais, senão surgindo de suas próprias experiências (Picchi 2015, p. 492):

A práxis, essa "reflexão sobre suas experiências", denuncia aquilo que se poderia chamar, no finalizar de uma obra, de técnica pessoal, a qual não se reduz apenas a uma busca, mas principalmente uma incessante procura pela 'verdade interior' do artista em realizar e como realizar a obra a um só tempo. Mário de Andrade se refere à técnica pessoal com muita ênfase, especialmente como "uma procura técnica de resolver o seu problema pessoal diante da obra de arte".

\section{2 - Aplicação criativa: a solução de problemas auto impostos}

Na segunda região da expertise composicional, coloca-se o problema auto imposto pelo compositor, cuja resolução é a própria obra. Neste caso, não se está tomando problema por obstáculo, mas sim por desafio que parte do insight, e de seu estudo e detalhe, tendo por norte o objetivo geral da composição. Não se trata, igualmente, de encontrar soluções corretas ou únicas para o problema pautado pelo compositor.

Muito embora esteja no horizonte composicional o objetivo, é sempre possível (e, algumas vezes, desejável) que, de um ponto de partida definido não se saiba exatamente qual a definição do ponto de chegada. $\mathrm{O}$ que não interfere com o fato da previsão que um compositor expert deve desenvolver, visto que compor é processo e a abertura mental deve estar sempre presente e alerta, inclusive no que diga respeito ao objetivo ou 'finalização' da composição.

Como as escolhas são feitas tendo em conta o domínio, principalmente sobre rejeições e restrições processuais, o desenvolvimento que se alia à técnica 
composicional - advindo sempre da, ou de uma, teoria - é fundamentalmente estético.

\section{5 - Expressão: Realização}

Embora tenhamos dividido, por assim dizer, os 'momentos' composicionais em geral em ideia, o trabalho do insight na busca de uma expertise que represente o domínio e o controle do processo criativo, seja ele já estabelecido ou apenas para aquela obra em particular e a técnica composicional resultante com o objetivo de construir a composição, como já situado e comentado, parece claro que o todo do processo composicional busque a expressão como finalidade primeira e última.

Sendo assim, o insight e o trabalho, a expertise e a técnica são facetas da mesma moeda sígnica, ou seja, a expressão do compositor.

Gostaríamos aqui de realizar um paralelo interessante e possível com uma obra fundamental da poética: o ensaio The Philosophy of Composition ou A Filosofia da Composição, de Edgar Allan Poe (1809-1849), escrito em 1845 e publicado em 1846 no Graham's Magazine onde, naquela ocasião, o poeta era o editor. Este ensaio foi escrito originalmente como uma conferência que nunca chegou a ser pronunciada.

Poe foi uma influência essencial e decisiva, em muitos casos, para grande número de escritores pósteros, da segunda metade do século XIX em diante. Neste escrito ele se transveste em crítico avant la lettre de si mesmo e escolhe, de sua produção poética, o famoso e polêmico poema The Raven, ou O Corvo, publicado em 29 de janeiro de 1845 no jornal The New York Evening Mirror ${ }^{\text {. }}$

O poema $O$ Corvo, que se tornou muito famoso e comentado em sua época e passou à posteridade como um dos poemas mais lidos e frequentados da poética ocidental, é uma obra de caráter narrativo e com um toque fantástico. $\mathrm{O}$ narrador, um estudante, se vê às voltas com a lembrança da amada que já se foi, naturalmente muito jovem - o traço romântico de emocionalidade e melancolia que, segundo o autor, encaminha a Beleza que ele escolhe - e é confrontado por um corvo que, apesar da descrição inicial de batidas à porta numa emulação de tentativa de entrar, adentra seu estúdio pela janela e pousa sobre um busto de Palas, formando um diálogo entre a consciência do rapaz (o pássaro emblemático) e a racionalização (Palas simbolizando o entendimento). Há muitas metáforas de maneiras de lidar com o sofrimento, como a luz, o veludo de uma

\footnotetext{
${ }^{8}$ Onde apareceu sem a assinatura de seu autor e pelo qual auferiu 10 dólares.
} 
poltrona, entre outras. Por fim, pelo fato de o corvo não responder aos questionamentos e angústias do rapaz senão por uma única palavra (que Poe bem coloca como uma síntese expressiva, Nevermore, ou Nuncamais), não há a possibilidade de eliminar tamanho sofrimento por meio da racionalização ou outro caminho, que não seja a continuidade da lembrança da amada dentro deste universo de melancolia e perda. Assim o estudante expulsa o corvo de seu ambiente, não antes do autor nos fazer perceber um relacionamento dos pensamentos e questionamentos por parte do rapaz a apenas aquela única resposta do animal, que se tornou o refrão famoso: Nevermore.

$\mathrm{O}$ que faz interessante o paralelo entre a composição musical e a composição do poema "analisada" em A Filosofia da Composição são as tantas similaridades e peculiaridades em relação à posição da teoria frente ao poeta criador - e ao compositor musical igualmente.

Poe confessa logo: "muitas vezes imaginei como seria interessante um artigo de revista escrito por um autor que quisesse - quer dizer, que pudesse detalhar, passo a passo, os processos através dos quais suas composições atingiram uma completa finalização" (Poe 2008, p. 19).

O ensaio se propõe mostrar, efetivamente, e, segundo intenção do autor, desprovido de metafísicas ou mistérios exotéricos, a maturação da técnica composicional enquanto expressão. E diz o poeta: “ A Beleza é o único terreno legítimo do poema", donde se pode, sem perdas, substituir poema por música. Imediatamente, porém, explica que "designo Beleza como o espaço do poema simplesmente porque se trata de uma regra óbvia da Arte que os efeitos devem derivar de causas diretas" (Poe 2008, p. 23, negrito meu). Poe está obviamente se referindo ao impacto emocional sempre pretendido pelo artista criador. E menciona que somente tendo em vista o objetivo, o 'fim da história', se pode manter o "tom [...] que aponte para o desenvolvimento da intenção" (idem, p.18).

Assim sendo, perora que nenhum detalhe da composição "pode ser atribuído a acidente ou intuição [...] o trabalho foi realizado passo a passo até o final com a precisão e a rígida consequência de um problema matemático" (idem, p. 20). Aqui temos duas das etapas já comentadas anteriormente, o proficiente e, digamos, total conhecimento da teoria para ter condições de "realizar passo a passo" o trabalho composicional; e a maturação deste conhecimento, através da vivência da teoria com o precípuo e fundamental objetivo de validar e suportar a verdade expressiva da criação e esta, a criação, como sendo um problema autoimposto pelo criador, de forma a, ao adotar soluções - e estar atento, pelo caminho, a modificações com o horizonte de eventos sempre em mira -, atingir a consecução que já, de partida do insight, lhe era pretendida.

Uma primeira atitude técnica desponta quando se refere à escolha do uso do "refrão": "como é comumente usado, o refrão, ou coro, não só se limita ao verso lírico, mas depende, para sua impressão, da força da monotonia - tanto em 
som quanto em pensamento. O prazer é derivado unicamente do sentido de identidade - de repetição" (Idem, ibidem).

Nota-se que de fato, em termos técnicos, a escolha da repetição, formalmente falando, tem a importância delimitatória e a construtora em música, mesmo primordialmente.

Predeterminado o processo técnico, vem a escolha do material (idem, p.25):

tendo me decidido por um refrão, a divisão do poema em estrofes era, é claro, uma consequência, com o refrão fechando cada estrofe. Este fechamento [...] devia ser sonoro [...] estando assim determinado o som do refrão, tornou-se necessário escolher uma palavra que contivesse esse som e, ao mesmo tempo, conservasse aquela melancolia que eu tinha predeterminado como sendo o tom da poesia.

Mostra-se a preocupação epistemológica, que redunda na estilística, de manter ao longo da composição a unidade e a coerência.

Percebe-se, também, que, segundo o poeta, era preciso "um pretexto para o uso contínuo da expressão nunca mais", asseverando, como já comentado, o problema a ser resolvido e a previsão do compositor como elemento condutor e de unificação.

De um ponto de vista exclusivamente técnico Poe diz (idem, p. 28-29) que seu primeiro objetivo

era originalidade [...] o fato é que a originalidade (a não ser em mentes de força muito rara) não é uma questão, como alguns supõem, de impulso ou intuição. Em geral, para ser conseguida, ela deve ser extremamente trabalhada e embora seja um grande mérito, para ser alcançada, ela exige mais negação do que invenção.

Neste passo fica clara a ideia de que a teoria deve previamente ser de perfeito conhecimento do compositor; mas não basta, pois, a exigência de 'negação' mais do que 'invenção' supõe a convivência da técnica composicional na direção da expertise, do domínio, por meio do trabalho ('extremamente trabalhada'), escolhas, como já situamos, principalmente sobre rejeições e restrições processuais: diretamente estéticas.

Assim, não qualquer expertise e sim a que envolve o objetivo primacial da expressão (idem, p. 29-30): “O efeito desta originalidade [...] é intensificado por outros efeitos pouco comuns, alguns inteiramente novos, que surgem de uma extensão da aplicação dos princípios de rima e aliteração".

Chamando, até esse momento, de "pré-considerações", o poeta se põe a escrever "pelo fim, onde todas as obras de arte deviam começar" (idem, p. 28), justificando que o objetivo, assim posto e claro na mente composicional, seria o 
parâmetro e a medida para o desenvolvimento da obra. Muito embora ficasse sujeito (e atento) às possibilidades de interferência e modificação que pudessem acontecer ao longo da composição enquanto trabalho e invenção - sempre, porém, dentro do plano previsto e, mais que isso, contaminado por ele.

Um elemento composicional que interessa a ambos, poética e composição, é o não uso do óbvio ou do lugar comum quando ele se apresente, visto que, a menos que faça parte da 'intenção' composicional, poderá macular ou até eliminar o efeito. Assim, o uso da expectativa, da prolongação de tensões, do contraste são elementos que vão tecnicamente, entretanto embebidos da expressividade, desenrolando o tecido composicional, com o objetivo de intensificar a impressão final, no dizer do poeta.

Por fim, todo o caminho empreendido é justificado pelo efeito final, usando a visão de Beleza propugnada por Poe como sendo, antikantianamente, passível de ser explicada e, mesmo, 'ensinada' pelo próprio artista criador. Uma Beleza derivada do efeito e do impacto advindos da rígida e perfeita formalização ideada e seguida por esse criador.

Advogando que para a obra existe a necessidade de uma certa dose de complexidade e de uma corrente oculta, mesmo que indefinida de sentido, o poeta designa o fim de sua composição fazendo com que o leitor disponha (Poe 2008, p. 34):

a mente em buscar uma moral em tudo o que foi previamente narrado. O leitor começa agora a ver o Corvo como sendo emblemático - mas é só no último verso da última estrofe que a intenção de torná-lo emblemático de Desolação e de Memória sem fim pode ser claramente percebida.

Enfim percebe-se a reserva de clímax final e o plano geral, agora se encaixando na intenção de caminho composicional do compositor: lógica, coerência e sempre interesse, como já dispunha Schoenberg (1996).

\section{6 - Considerações Finais}

A inspiração, ou ideia, e o insight, em princípio e a realização, ou elaboração, afinal são e continuarão a ser o percurso da composição musical, permeada pela teoria que, vivenciada sempre através do repertório e manipulação consciente do compositor, constituindo sua técnica, terá por finalidade a expressão deste enquanto necessidade criativa.

Mas com o desenrolar da história, essa atitude tão humana, que é a necessidade de expressão por meio da criação, veio sempre aliada a outra característica da arte da humanidade: a originalidade. É possível perceber que a 
busca da originalidade na criação em todos os tempos passa pela constante preocupação com a 'linguagem' musical, com a experimentação técnica ou com o virtuosismo artesanal. Até que isto nos remeta, na contemporaneidade, a uma situação cada vez mais insurgente na composição qual seja a técnica como a própria finalidade expressiva, ao ponto em que a própria técnica, estabelecida enquanto tal e conhecida junto à expressão musical, se faça obra.

Desde os inícios do século XX, a revolução da 'linguagem' musical mais e mais se instala, como se sabe, numa crescente busca da originalidade, aquela técnica construtiva da obra musical, terminando por abarcar e envolver todo o processo de conteúdo expressivo da música contemporânea, caminho em vista do novo, fazendo com que os próprios nichos técnicos polemizassem técnica construtiva e conteúdo expressivo.

Durante as décadas de 1960 e 1970 houve uma agravante extrema dessa situação, de forma que certa mentalidade de vanguarda pretendeu polarizar a ontologia musical, isto é, a pertinência das realizações composicionais que simplesmente não se enquadrassem nas sempre novas e experimentais visões técnicas de composição, como sendo um único e possível caminho para a música contemporânea. De tal modo que aparentemente advogava-se uma abolição da efetiva técnica composicional em favor de aberturas e liberdades outras que não fossem 'enclausuradas' pelas escolhas, restrições e rejeições. $\mathrm{O}$ uso de acaso e possivelmente o não planejado, não estudado, não teorizado parecia ser novo horizonte da ideação constitutiva. Entretanto, como qualquer movimento radical ou propenso à radicalização, após sedimentações e afirmações, tendeu a uma relativização; com isso uma certa estabilização, digamos assim, vigente a uma integralidade expressiva da obra se revitalizou, convivendo mais ou menos pacificamente com todas as experiências e conquistas até então assestadas junto a visões novas e mesmo polêmicas em relação à definição do que fosse música; as 'tradições' havidas e inventadas, antes questionadas, foram retomadas e atualizadas.

Porém isso tudo se fez de maneira estratificada, em grupos com conceitos mais rígidos ou mais abertos, de forma que se pudesse seguir estilisticamente esse caminho ou aquele, ou seja de modo estamentário. O que não modificou o que houve e continuou havendo, isto é, aquela separação típica do pósmodernismo em cujo seio o valor e a validade parecem se bastar apenas intrinsecamente, sem efetivamente se tocarem.

Retomando a questão do início, onde se poderia colocar a teoria relativamente ao compositor, diríamos que a era dos estilos fechados e influências já passou. Mas não a da estilística, obra a obra ou geral, sob a égide da técnica composicional eivada da teoria exercendo sua influência suprapartidária sobre técnicas composicionais, individuais ou coletivas, que garantam a verdade expressiva em pensamento organizado. 


\section{Referências}

1. Andrade Mário Raul de Moraes. 1938. O Artista e o Artesão. In: O Baile das Quatro Artes. São Paulo: Martins.

2. Berio, Luciano. s.d. Entrevista sobre música (realizada por Rossana Dalmonte). Trad. Alvaro Lorencini e Letizia Zini Nunes. Rio de Janeiro: Civilização Brasileira,

3. Ferraz, Silvio. 2005. Livro das Sonoridades: [notas dispersas sobre composição]. Rio de Janeiro: 7Letras.

4 . (org.). 2007. Notas. Atos. Gestos. Rio de Janeiro: 7Letras.

5. Heidegger, Martin. 1999. A origem da obra de arte. Trad. Maria da Conceição Costa. Lisboa: Edições 70.

6. Morgenstern, Sam (ed.). 1956. Composers on Music. An Anthology of Composers Writings from Palestrina to Copland. New York: Pantheon Books.

7. Nogueira, Marcos. 2010. A semântica do entendimento musical. In: Ilari, Beatriz Senoi e Araújo, Roseane Cardoso de (Orgs). Mentes em Música. Curitiba: Editora UFPR.

8. Picchi, Achille. 2015. O Novo e o Original. Revista da Tulha, vol. 1, no 2.

9. Schoenberg, Arnold. 1996. Fundamentos da Composição Musical. Trad. Eduardo Seicman. $3^{\underline{a}}$ ed. São Paulo: EDUSP.

10. Sloboda, John A. 2008. A Mente Musical: a psicologia cognitiva da música. Trad. Beatriz Ilari e Rodolfo Ilari. Londrina: EDUEL.

11. Stravinsky, Igor. 1996. Poética Musical. São Paulo: Martins Fontes. 